\title{
A IMPORTÂNCIA DOS PROJETOS DE EXTENSÃO PARA A SENSIBILIZAÇÃO AMBIENTAL: UM ESTUDO DE CASO NA UNIVERSIDADE FEDERAL DE UBERLÂNDIA
}

\author{
Eunir Augusto Reis Gonzaga ${ }^{1}$ \\ Marina Maria Eliete da Silva ${ }^{2}$ \\ Euclides Honório de Araújo ${ }^{3}$
}

\begin{abstract}
RESUMO: A Diretoria de Sustentabilidade Ambiental (DIRSU), unidade administrativa da Prefeitura Universitária (PREFE) da Universidade Federal de Uberlândia (UFU), empenhouse em incentivar ações sociais vinculadas ao meio ambiente, buscando compreender como ações extensionistas podem contribuir para a sensibilização ambiental da comunidade. Analisou-se a viabilidade de executar projetos de extensão para atender às prerrogativas legais, no tocante à capacitação e sensibilização ambiental. A metodologia utilizada foi exploratóriodescritiva, com abordagens qualitativa e quantitativa. Foram realizadas dezesseis ações ao longo do ano de 2013, promovidas pela PREFE em parceria com unidades acadêmicas e administrativas, no intuito de atender à demanda dos diversos segmentos da sociedade no que tange à problemática ambiental. Observou-se, dessa forma, que projetos e ações de educação ambiental que promovam a não geração, a redução, a reutilização e a reciclagem, dentre outros, são ferramentas importantes para a implementação dos instrumentos presentes na Política Nacional de Educação Ambiental (PNEA).
\end{abstract}

PALAVRAS-CHAVE: Sensibilização ambiental. Comunidade acadêmica. Extensão universitária.

\section{The importance of outreach projects for environmental awareness: a case study in the Federal University of Uberlândia, state of Minas Gerais, Brazil}

\begin{abstract}
The Environmental Sustainability sector of Federal University of Uberlândia (UFU) endeavored to encourage social actions related to the environment, seeking to understand how extension actions can contribute to environmental community outreach. It was analyzed the feasibility of performing extension projects to meet the legal prerogatives regarding training and environmental awareness. The methodology was exploratory and descriptive, with qualitative and quantitative approaches. Throughout 2013, it was carried out 16 actions promoted by the university with academic and administrative units in order to meet the demands of various segments of society regarding environmental issues. It was observed that projects and environmental education activities that promote non-generation, reduction, reuse and recycling, among others, are important tools for the implementation of tools available in Environmental Education National Policy (PNEA).
\end{abstract}

KEYWORDS: Environmental awareness. Academic community. University extension.

\footnotetext{
${ }^{1}$ Mestrando em Meio Ambiente e Qualidade Ambiental no Instituto de Ciências Agrárias da Universidade Federal de Uberlândia UFU (euniraugusto@gmail.com).

${ }^{2}$ Graduanda em Gestão em Saúde Ambiental no Instituto de Geografia da Universidade Federal de Uberlândia (marinamariaes@hotmail.com).

${ }^{3}$ Doutor em Engenharia Química pela Universidade de São Paulo, professor titular da Universidade Federal de Uberlândia, onde atua como diretor de sustentabilidade ambiental (euclides@ufu.br).
} 


\section{INTRODUÇÃO}

Algumas questões ambientais, como o aquecimento global, o esgotamento de recursos não renováveis, poluição de rios, solos e ar, passaram a ser discutidas e enfrentadas no século XX. Com o avanço da modernidade, outra questão que passa a ser muito discutida e merece destaque são os resíduos sólidos, devido à sua complexidade (BRASIL, 2008).

A civilização chega ao limiar do século XXI como a civilização dos resíduos, marcada pelo desperdício e pelas contradições de um desenvolvimento industrial e tecnológico sem precedentes na história da humanidade, enquanto populações inteiras são mantidas à margem, não só dos benefícios de tal desenvolvimento, mas das condições mínimas de subsistência (FERREIRA, 1995).

Para minimizar o impacto causado pelas ações antrópicas, é preciso que se desenvolvam atividades direcionadas à sensibilização ambiental, sendo uma delas a educação ambiental, vista como capaz de prover a mudança de hábitos e condutas de ações em relação positiva ao meio ambiente, considerando toda a sua complexidade (PEDRINI, 2000). Desse modo, a educação ambiental precisa ser abordada da seguinte forma:

A falta de educação, e em especial a ambiental, surge como um defeito entre aqueles que têm o papel de intervir nos ambientes naturais em maior ou menor intensidade. A educação ambiental é uma alternativa para orientar as atitudes humanas no seu meio natural e social, pois, simboliza a busca de um novo pensamento na área rural e também na urbana, na tentativa de fazer com que os agentes envolvidos percebam a visão da totalidade e não no mero papel individual dentro de sua cadeia social. (DIAS, 1994, p. 64).

Segundo Pereira (1993, p. 35), é necessário

Analisar o conceito de educação ambiental, refletir acerca das relações do ser humano com o meio ambiente e sua aplicação no cotidiano do aluno. Não basta repassar o conhecimento, é preciso que aconteça um retorno da aprendizagem e mudanças de comportamento. Não basta também ser consciente, é preciso que cada um faça a sua parte, detectar as causas e descobrir soluções.

O processo educativo, na visão de Martins (2012), é a humanização plena, no sentido de consolidar as capacidades ontológicas desenvolvidas pelos indivíduos. É preciso ressaltar que, no âmbito das universidades públicas brasileiras, a tríade ensino-pesquisa-extensão apresentase como uma de suas maiores virtudes e expressão de compromisso social (MARTINS, 2012). A relação entre essas três esferas, quando bem articuladas, conduz a mudanças significativas nos processos de ensino e de aprendizagem, fundamentando, didática e pedagogicamente, a formação profissional, sendo que estudantes e professores constituem-se, efetivamente, em sujeitos do ato de aprender, de ensinar e de formar profissionais e cidadãos.

A pesquisa e a extensão, em interação com o ensino, com a universidade e com a sociedade, possibilitam operacionalizar a relação entre teoria e prática, a democratização do saber acadêmico e o retorno desse saber à universidade, testado e reelaborado. (DIAS, 2009, p. 39). 
Assim, a Universidade deve recomendar a indissociabilidade entre o ensino, a pesquisa e a extensão, fator fundamental para a mudança de hábitos, condutas de ações e conhecimentos da sociedade (LEITA; NUNES, 2009).

De acordo com Moraes (1998), as atividades em extensão não podem ser reduzidas a artifícios para complementar orçamentos e produzir saldos em caixa. Para o autor, a extensão deve ser entendida como extensão de pesquisa e ensino, e não pesquisa e ensino como extensão de serviços e convênios.

Compreende-se, então, que para "educar para as três esferas acima referidas, nas quais, em última instância, é construída a existência de todos os indivíduos, implica ter-se o desenvolvimento do 'sujeito práxico' como objetivo educacional" (MARTINS, 2012, p. 3).

\section{METODOLOGIA}

Para o estudo, foram utilizados como materiais projetos de extensão com vistas à questão ambiental, realizados no ano 2013, promovidos pela Prefeitura (PREFE) da Universidade Federal de Uberlândia, por meio de sua Diretoria de Sustentabilidade (DIRSU).

Utilizou-se, também, o Sistema de Registro e Informação de Extensão (SIEX) com ano base definido para 2013, unidade Reitoria (REITO) e subunidade (PREFE).

O procedimento utilizado para a execução correta da metodologia foi elaboração de tabelas, por meio das quais foram tabuladas as informações pertinentes à identificação e quantificação dos públicos sensibilizados da comunidade, transformando-os em agentes ambientais multiplicadores.

Os equipamentos utilizados foram estações de trabalho, com sistema operacional Windows 7 , fornecido pelo fabricante dos aparelhos licitados, e programas livres, com destaque ao navegador Mozilla Firefox e sistema de planilhas eletrônicas LibreOffice Calc.

Por meio do SIEX, foram identificados e classificados os projetos por tabulação. Os dados extraídos dos projetos foram compartilhados em nuvem, pela ferramenta Google Drive. Em seguida, foram identificados o objetivo geral e os específicos de cada projeto.

Como resultados, obteve-se o quantitativo de ações promovidas para sensibilização ambiental, contabilizando os públicos diretos e indiretos atingidos.

Assim sendo, o objetivo geral deste estudo foi analisar as ações de sensibilização ambiental, a partir de projetos de extensão apoiados pela PREFE, por meio da DIRSU e em parceria com a Diretoria de Extensão. Já os objetivos específicos foram compreender as ações dos atores sociais em prol do meio ambiente, norteadas pela da Política Nacional de Educação Ambiental (PNEA); explicar como foram estruturados os projetos de extensão; e, por último, relacionar os projetos de extensão na UFU com a sensibilização ambiental. 


\section{RESULTADOS}

Os objetos analisados foram projetos de extensão cadastrados na ferramenta SIEX e coletados pelo seu sistema interno de busca a partir das categorias "ano base 2013", "unidade REITO" e "sub-unidade PREFE", buscando verificar o público-alvo atingido direta e indiretamente pelas ações extensionistas.

Observou-se que a DIRSU promoveu, em parceria com a DIREC, um total de dezesseis projetos de extensão no ano 2013, como apresentado na Tabela 1:

Tabela 1- Projetos de extensão da PREFE, em 2013, catalogados na plataforma SIEX.

\begin{tabular}{|c|c|c|c|c|}
\hline $\begin{array}{l}\text { Ação SIEX } \\
N^{\circ}\end{array}$ & Nome do Projeto de Extensão & $\begin{array}{l}\text { Público } \\
\text { Direto }\end{array}$ & $\begin{array}{l}\text { Público } \\
\text { Indireto }\end{array}$ & $\begin{array}{l}\text { Público } \\
\text { Total }\end{array}$ \\
\hline 11456 & $\begin{array}{l}\text { PREFE - Manual para gerenciamento de resíduos } \\
\text { químicos }\end{array}$ & 100 & 30000 & 30100 \\
\hline 11296 & $\begin{array}{l}\text { PREFE - Palestra de capacitação para funcionários } \\
\text { terceirizados da limpeza }\end{array}$ & 30 & 100 & 130 \\
\hline 11298 & PREFE - Extensão e Cultura em Mostra & 100 & 500 & 600 \\
\hline 11280 & $\begin{array}{l}\text { PREFE - Palestra de capacitação para funcionários } \\
\text { terceirizados de jardinagem }\end{array}$ & 30 & 100 & 130 \\
\hline 11615 & PREFE - Integração no bairro Jardim Brasília & 30 & 7000 & 7030 \\
\hline 11371 & $\begin{array}{l}\text { PREFE - Palestra para funcionários do hospital de } \\
\text { clínicas }\end{array}$ & 30 & 200 & 230 \\
\hline 11367 & PREFE - Tropicália Noites e Dias & 100 & 300 & 400 \\
\hline 11485 & $\begin{array}{l}\text { PREFE - Exposição "Viva Arte" de artesanato } \\
\text { sustentável }\end{array}$ & 30 & 300 & 330 \\
\hline 11617 & $\begin{array}{l}\text { PREFE - Conscientização sobre o descarte e } \\
\text { destinação final de resíduos sólidos: uma experiência } \\
\text { no "Samba mandou me chamar" }\end{array}$ & 10 & 5000 & 5010 \\
\hline 11473 & PREFE - Oficina de artesanato sustentável & 30 & 300 & 330 \\
\hline 11483 & $\begin{array}{l}\text { PREFE - Seminário sobre resíduos químicos nas } \\
\text { instituições de ensino }\end{array}$ & 370 & 30000 & 30370 \\
\hline 11460 & PREFE - Plano de redução de consumo de papel & 50 & 30000 & 30050 \\
\hline 11447 & PREFE - UFUzuê Itinerante & 100 & 3000 & 3100 \\
\hline 11493 & $\begin{array}{l}\text { PREFE - Exposição de técnicas de design com } \\
\text { reutilização de pneus }\end{array}$ & 500 & 5000 & 5500 \\
\hline 11578 & PREFE - Integração no bairro Luizote & 30 & 7000 & 7030 \\
\hline 11577 & $\begin{array}{l}\text { PREFE - Conscientização sobre o descarte e } \\
\text { destinação final de resíduos sólidos: uma experiência } \\
\text { no "Samba mandou me chamar" }\end{array}$ & 10 & 5000 & 5010 \\
\hline
\end{tabular}

Fonte: Os autores (2013).

O "Manual para gerenciamento de resíduos químicos" teve como objetivo proporcionar informações pertinentes às técnicas básicas para o gerenciamento dos resíduos produzidos nas 
dependências da UFU, oriundos das atividades de ensino, pesquisa e extensão, que possam impactar negativamente a qualidade e a disponibilidade dos recursos naturais para futuras gerações. A correta utilização viabiliza o funcionamento do Laboratório de Resíduos Químicos (LRQ) da DIRSU, unidade administrativa da PREFE, situada no Bloco 5J do campus Santa Mônica, padronizando e normatizando o gerenciamento, a minimização e o manejo dos resíduos químicos.

A "Palestra de capacitação para funcionários terceirizados da limpeza", realizada em maio/2013, teve como objetivo capacitar e sensibilizar os técnicos terceirizados de conservação e limpeza a respeito da importância das medidas sustentáveis vinculadas ao meio ambiente, melhorando a qualidade de vida e promovendo um ambiente de trabalho saudável.

Figura 1 - Funcionários terceirizados da limpeza e conservação em atividade de capacitação.

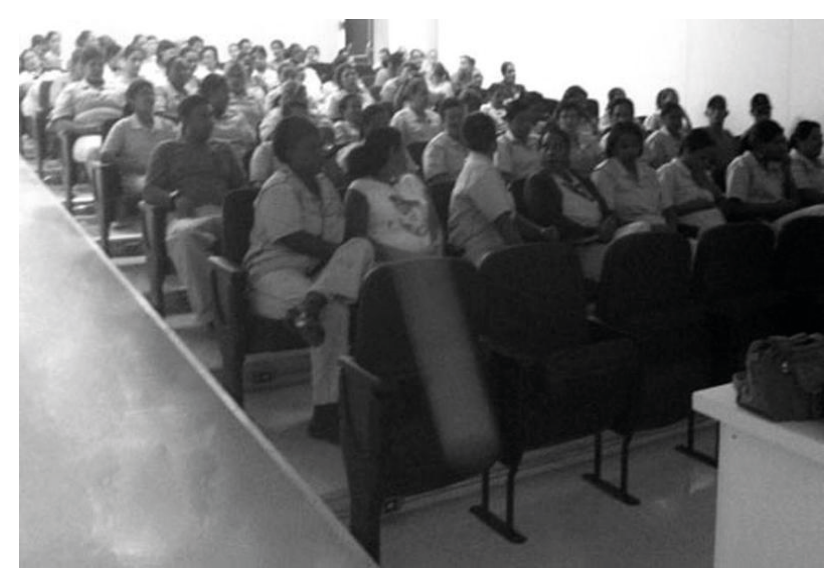

Autora: Rayane Pires Cornélio (2013).

O projeto homônimo ao evento ocorrido em junho/2013 - "Extensão e Cultura em Mostra" refere-se a uma exposição na qual se buscou mostrar a importância da separação dos resíduos secos e úmidos, com atividades práticas para promover a educação ambiental. Os participantes puderam ver, na prática, como a coleta seletiva beneficia associações e cooperativas de catadores de materiais recicláveis, gerando renda para famílias carentes e garantia de trabalho mais digno.

A "Palestra de capacitação para funcionários terceirizados de jardinagem" foi realizada em junho/2013 com o objetivo de capacitar e conscientizar os técnicos terceirizados de jardinagem sobre a importância das medidas sustentáveis vinculadas ao meio ambiente, melhorando a qualidade de vida e promovendo um ambiente de trabalho saudável.

No "Integração no bairro Jardim Brasília", realizado no mês de junho/2013, foi feita uma apresentação sobre o Planejamento de Gestão em Resíduos Sólidos (PGRS) da UFU, atendendo à demanda da Lei $\mathrm{n}^{\circ} 12.305 / 10$.

Em julho/2013, foi realizada uma palestra voltada para a comunidade que frequenta o Hospital de Clínicas (HC), a fim de capacitar e conscientizar os atores sociais a respeito da importância das medidas sustentáveis vinculadas ao meio ambiente, melhorando a qualidade de vida e promovendo um ambiente de trabalho saudável. 
No projeto "Tropicália Noites e Dias", ocorrido em agosto/2013, a PREFE/DIRSU forneceu suporte em infraestrutura para esse evento de extensão, promovido pela Diretoria de Cultura (DICULT), no intuito de promover conscientização ambiental para a comunidade participante.

A “Exposição 'Viva Arte' de Artesanato Sustentável”, ocorrida em setembro/2013, visou mostrar a importância da separação dos resíduos secos e úmidos, considerando que atividades semelhantes são também uma forma prática de promover educação ambiental. Os participantes puderam ver, na prática, como a coleta seletiva beneficia associações e cooperativas de catadores, gerando renda para famílias carentes e garantia de trabalho mais digno.

Figura 2 - "Exposição 'Viva Arte' de Artesanato Sustentável", na Biblioteca do campus Santa Mônica.

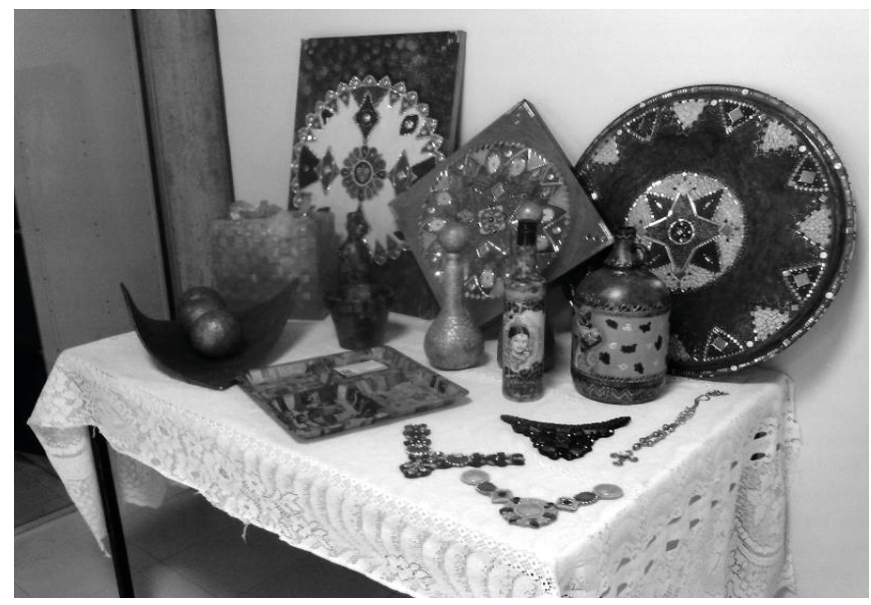

Autora: Letícia França Ribeiro (2013).

"Conscientização sobre o descarte e destinação final de resíduos sólidos: uma experiência no 'Samba Mandou Me Chamar'", foi realizado, em parceria com a DICULT, no mês de setembro/2013. Na ação, voltada para a comunidade externa, forneceu-se suporte em infraestrutura para o evento de extensão, no intuito de promover sensibilização ambiental em evento cultural.

No mês de setembro/2013, foi realizada a "Oficina de artesanato sustentável", buscando promover a conscientização ambiental, por meio da criação de peças artísticas, a partir de materiais que iriam para aterros sanitários. Essa prática oferece oportunidade de geração de renda, pois inúmeros materiais podem ser aplicados, com baixo custo e resultados surpreendentes, transformando o que era visto como "lixo" em peças de decoração e utilidade doméstica.

Também em setembro/2013, foi realizado o "Seminário sobre resíduos químicos nas instituições de ensino", com o objetivo de promover a mobilização da comunidade, a discussão sobre o crescimento do número de resíduos químicos perigosos e o seu impacto nocivo para o meio ambiente e para a saúde da população, divulgando o lançamento do Manual para Gerenciamento de Resíduos Químicos. 
Figura 3 - Seminário sobre resíduos químicos nas instituições de ensino.

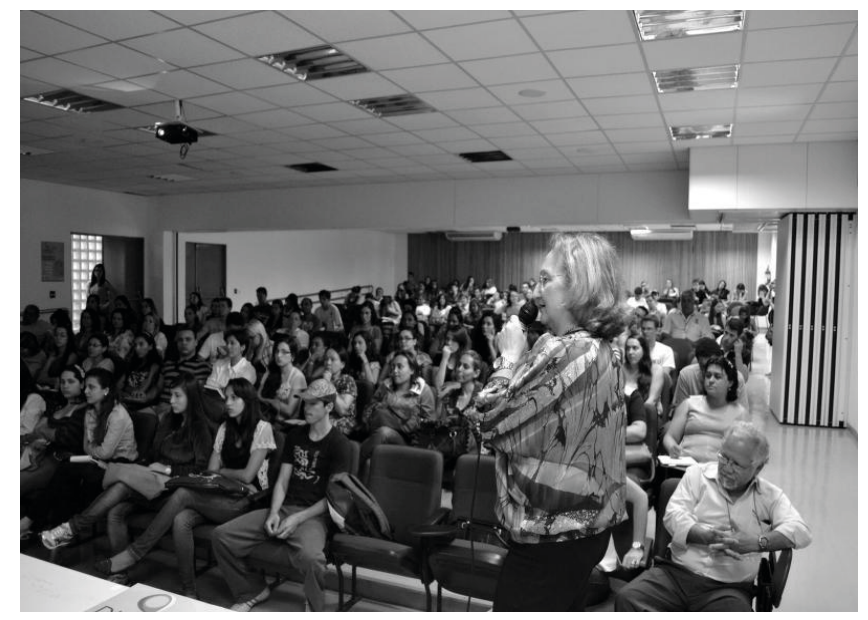

Autora: Letícia França Ribeiro (2013).

O "Plano de redução de consumo de papel", realizado em setembro/2013, objetivou elaborar planos de ação referentes ao PGRS, com o objetivo de reduzir o consumo de papel na UFU e, consequentemente, adotar uma alternativa ambientalmente correta para o seu descarte - com utilização do que ainda pode ser aproveitado por todos que utilizam os espaços das bibliotecas - e posterior reciclagem de todo o papel coletado, minimizando a contaminação desse tipo específico de resíduo sólido com materiais orgânicos.

No projeto "UFUzuê Itinerante", realizado pela DICULT no mês de setembro/2013, a PREFE/DIRSU forneceu suporte em infraestrutura para esse evento de extensão, no intuito de promover conscientização ambiental para a comunidade participante.

Em outubro/2013, foi realizada a "Exposição de técnicas de design com reutilização de pneus", no intuito de mostrar a importância da reutilização e reciclagem de resíduos que poderiam superlotar aterros e lixões, depositando, na natureza, materiais tóxicos e de difícil decomposição (caso dos pneus). Também foi uma forma de promover a educação ambiental, conscientizando os visitantes sobre as práticas para o desenvolvimento sustentável.

O projeto "Integração no bairro Luizote", ocorreu no mês de novembro/2013 e teve como objetivo apresentar à comunidade externa o PGRS da UFU, atendendo à demanda da Lei $\mathrm{n}^{\circ}$ $12.305 / 10$.

Por fim, em dezembro/2013, realizou-se o projeto "Conscientização sobre o descarte e destinação final de resíduos sólidos: uma experiência no 'Samba Mandou me Chamar"” com o objetivo de fornecer suporte em infraestrutura para esse evento de extensão, desenvolvido pela DICULT, no intuito de promover conscientização ambiental aos participantes.

\section{DISCUSSÃO}

Compreende-se, portanto, que as atividades de extensão, desenvolvidas com o viés da sustentabilidade, são uma importante maneira de promover sensibilização ambiental. 
Para este estudo, foi preciso realizar o montante uma pesquisa bibliográfica, a fim de discernir as esferas ensino, pesquisa e extensão, extraindo desta última suas principais características, considerando o objeto ambiental como prioridade nas ações propostas.

O saldo final do trabalho foi positivo, haja vista o cumprimento de todas as atividades propostas. $O$ trabalho atendeu à prerrogativa legal, em atendimento à Lei $n^{0} 9.795 / 99$, pois suas ações foram estratégicas, promovendo tanto a participação na produção de informação e conteúdos educativos, articulando resultados em longo prazo, como também ações continuadas de suporte para outras unidades acadêmicas e administrativas com vistas à comunidade externa, tornando os participantes agentes multiplicadores da problemática ambiental nos espaços que frequentam fora dos campi da UFU.

Foram beneficiados, com bolsas de extensão, 17 graduandos dos cursos de Ciências da Computação, Comunicação Social, Design de Interiores, Engenharia Ambiental, Engenharia Química, Geografia, Química Industrial, Relações Internacionais e Sistemas de Informação, oportunidade ímpar para os acadêmicos colocarem em prática o conhecimento adquirido em sala de aula e promover benefícios para a comunidade em geral.

É preciso ressaltar que todas as atividades desenvolvidas no ano base 2013 tiveram apoio financeiro de um projeto mais amplo, cuja unidade proponente foi a PROEX, por meio de sua sub-unidade Secretaria da PROEX. Foram viabilizados $\mathrm{R} \$ 60.000,00$ reais, por meio da Ação SIEX $n^{\circ} 10.594$, verba proveniente de emenda parlamentar.

\section{CONSIDERAÇÕES FINAIS}

O propósito principal deste estudo foi o levantamento das ações oficializadas na plataforma SIEX, considerando o ano base 2013. Além da abordagem quantitativa dos projetos de extensão pesquisados, no tocante ao público almejado, avaliou-se, qualitativamente, cada projeto, por meio de seus objetivos gerais e específicos. Os resultados obtidos foram um total catalogado no SIEX de dezesseis ações em extensão.

O estudo limitou-se à utilização de recursos do Centro de Custos da PROEX, viabilizados por meio de edital da DIREC, com verba proeminente de Emenda Parlamentar de 2012. Evidenciou-se a importância da PREFE/DIRSU para a sensibilização ambiental da comunidade externa. A principal contribuição foi viabilizar ações extensionistas direcionadas ao meio ambiente, em formato continuado, por meio das unidades administrativas da UFU.

Compreende-se, dessa forma, que a extensão é um dos caminhos que, por essência, traz retorno das ações aos atores sociais no âmbito da UFU.

\section{REFERÊNCIAS}

BRASIL. Resíduos sólidos: gerenciamento de resíduos de serviços de saúde: guia do profissional em treinamento. Nível 2 / Ministério das Cidades. Secretaria Nacional de Saneamento Ambiental (Org.). Brasília, DF: Ministério das Cidades, 2008. 
DIAS, A. M. L. Discutindo caminhos para a indissociabilidade entre ensino, pesquisa e extensão. Revista Brasileira de Docência, Ensino e Pesquisa em Educação Física, Cristalina, v. 1, n. 1, p. 37-52, 2009.

DIAS, G. F. Educação ambiental: princípios e práticas. 3. ed. São Paulo: Gaia, 1994.

FERREIRA, J. A. Resíduos sólidos e lixo hospitalar: uma discussão ética. Caderno de Saúde Pública, Rio de Janeiro, v. 11, n. 2, p. 14-320, abr.-jun. 1995.

LEITA, M. T. F. da; NUNES, B. M. V. T. Centro rural universitário de treinamento e ação comunitária: um resgate histórico 1975-1986. Texto Contexto Enfermagem, Florianópolis, v. 18, n. 3, p. 427-435, jul.-set. 2009.

MARTINS, L. M. Ensino-pesquisa-extensão como fundamento metodológico da construção do conhecimento na universidade. São Paulo: Editora da Unesp, 2012.

MORAES, R. C. C. de. Universidade hoje: ensino, pesquisa, extensão. Educação \& Sociedade, Campinas, v. 19, n. 63, ago. 1998.

PEDRINI, A. de G. Educação ambiental: reflexões e práticas contemporâneas. 3. ed. Petrópolis: Vozes, 2000.

PEREIRA, A. B. Aprendendo ecologia através da educação ambiental. Porto Alegre: Sagra-DC Luzzatto, 1993. 